\title{
Controlled synthesis of novel reactive cationic copolymers of 3-chloro-2- hydroxypropylmethyldiallylammonium chloride and dimethyldiallylammonium chloride [P(CMDA-DMDAAC)s]: designed as useful polycationic dye-fixatives on cotton fabric
}

\author{
Yikai Yu • Yuejun Zhang \\ Received: 2 January 2012/ Accepted: 5 March 2012/Published online: 20 March 2012 \\ (C) The Author(s) 2012. This article is published with open access at Springerlink.com
}

\begin{abstract}
A series of novel reactive cationic copolymers [P(CMDA-DMDAAC)s] of 3-chloro-2-hydroxypropylmethyldiallylammonium chloride (CMDA) and dimethyldiallylammonium chloride (DMDAAC), were designed as useful polycationic dye-fixatives on cotton fabric. The structures of obtained P(CMDA-DMDAAC)s could be controlled by varying molar ratios of raw materials of CMDA to DMDAAC during polymerization, and their molecular weights were possibly controlled by adjusting different polymerization conditions. The results showed that under the same conditions when the polymerization temperatures were kept at $60{ }^{\circ} \mathrm{C}$ for $6 \mathrm{~h}$ and then heated to $70{ }^{\circ} \mathrm{C}$ for $2 \mathrm{~h}$, when the initial monomer concentrations (w/w) were increased from 23 to $40 \%$ and the initiator amounts were gradually decreased from 7 to $6 \%$, a series of novel products P(CMDA-DMDAAC)s with 2-20\% molar contents of reactive units (CMDA units) in main chains and controlled intrinsic viscosities of $0.15-0.76 \mathrm{dL} / \mathrm{g}$ were successfully synthesized, which were as designed and could be expected as novel useful reactive polycationic dyefixatives on cotton fabric.
\end{abstract}

Keywords Dimethyldiallylammonium chloride · 3-chloro-2hydroxypropylmethyldiallylammonium chloride $\cdot$ Copolymers .

Controlled synthesis - Molecular weight - Reactive cationic units · Dye-fixatives

\footnotetext{
Y. Yu · Y. Zhang (ه)

School of Chemical Engineering, Nanjing University of Science and Technology, Nanjing 210094, China

e-mail: zhyuejun@mail.njust.edu.cn

Y. Yu

College of Chemistry and Chemical Engineering, Jiangxi Normal University, Nanchang 330022,

China
} 


\section{Introduction}

Cotton fabric is the most widely welcomed textile in the world [1]. Dyed cotton should have high colorfastness to the usual repeated domestic launderings [2]. Dyefixatives are usually selected to improve the fastness properties of dyes on cotton fabrics [3].

Up to now, poly (dimethyldiallylammonium chloride) (PDMDAAC) has been used as the optimum dye-fixative with a view to enhance the uptake of anionic dyes on cotton fabrics, and the mechansim of interactions involved can be interpreted as the participation of electrostatic forces between the dyes and the basic cationic groups in the polymer, which is the polymer derived from radical homopolymerization of dimethyldiallylammonium chloride (DMDAAC) [4-6]. The PDMDAAC dye-fixatives can be widely applied in the fixing of different dyes on cotton fabrics due to the similar conformational structures between cellulose and the unit of DMDAAC, which would be expected to contribute to strong interactions [7-10]. However, PDMDAAC exhibits usually poor rubbing fastness, especially poor wet rubbing fastness, due to the possible dissociation of color lakes also based on electrostatic forces which are caused by the effect of water molecules, resulting in the decolorization of dyes from the cotton fabric [11]. This has prompted researchers to synthesize new series of promising modified PDMDAAC dye-fixatives.

It has been indicated that the fastness performances of resin dye-fixatives (polymer dye-fixatives) varied according to their molecular weights [12], and in our contribution, the authors discovered that those PDMDAAC dye-fixatives with controlled molecular weights characterized by intrinsic viscosities of $0.24-0.47 \mathrm{dL} / \mathrm{g}$ can exhibit better dye-fixing performances because low intrinsic viscosities would make the interactions with dyes very weak, resulting in the poor dye-fixing performances, whilr too high intrinsic viscosities would make it very difficult to penetrate into cotton fabrics to interact with the dyes, also resulting in the poor dyefixing performances, thereby the polycationic dye-fixatives with their suitable molecular weights should be welcomed [13-15]. On the other hand, if a few contents (e.g., below $20 \%$ molar contents) of reactive units, which can bring about the linking reactions with the hydroxyl groups of cotton (cellulose) to form a covering film on the cotton surface, are incorporated into the backbones of PDMDAAC, the dyefixing performances of those modified PDMDAAC can also be improved [16-21]. Therefore, it can be deduced that those cationic polymers of modified PDMDAAC, derived from the further incorporation of controlled contents such as below $20 \%$ molar contents of reactive units into the backbones of the molecular-weightcontrolled PDM with the controlled intrinsic viscosities of $0.24-0.47 \mathrm{dL} / \mathrm{g}$ or similar, may be expected to be more useful polycationic dye-fixatives on cotton fabric. Further, since, recently, many of the attempts to improve the dye exhaustion and fastness properties on cotton have included the use of 3-chloro-2-hydroxy propyl derivatives due to the reactions with the hydroxyl groups of cotton (cellulose) [19], they could be used as the new reactive groups to be incorporated into the backbones of PDMDAAC. Thus, the authors expected that a series of novel reactive cationic copolymers of 3-chloro-2-hydroxypropylmethyldiallylammonium chloride (CMDA) and DMDAAC, P(CMDA-DMDAAC)s, as the new candidates for useful 
polycationic dye-fixatives on cotton fabric, could be designed by further incorporation of controlled contents of new reactive units containing 3-chloro-2-hydroxy propyl groups (CMDA) into the backbones of the molecular-weight-controlled PDM, especially as this has not been reported in the literature. The novel $\mathrm{P}(\mathrm{CMDA}-\mathrm{DMDAAC}) \mathrm{s}$ were synthesized by copolymerization of CMDA and DMDAAC according to Scheme 1. As designed, the structures of obtained $\mathrm{P}(\mathrm{DHAC}-\mathrm{DMDAAC}) \mathrm{s}$ can be controlled by varying the molar ratios of raw materials of CMDA to DMDAAC from 2/98 to 20/80 during polymerization, and their molecular weights represented by the intrinsic viscosities of $0.24-0.47 \mathrm{dL} / \mathrm{g}$ or similar were possibly controlled by adjusting different polymerization conditions.

\section{Experimental}

Materials

Ammonium persulfate (APS) was purchased from Yixing Tianpeng Fine Chemical (China). Dimethyldiallylammonium chloride (DMDAAC) was purchased from Luyue Chemical (China). CMDA was synthesized according to the literature [22, 23].

Controlled synthesis of $\mathrm{P}(\mathrm{CMDA}-\mathrm{DMDAAC}) \mathrm{s}$ : design and process

Design for controlled synthesis of $P(C M D A-D M D A A C) s$

A series of novel $\mathrm{P}(\mathrm{CMDA}-\mathrm{DMDAAC}) \mathrm{s}$, which were designed as useful polycationic dye-fixatives on cotton fabric, could be synthesized by copolymerization of CMDA and DMDAAC as shown in Scheme 1. As designed, the structures of
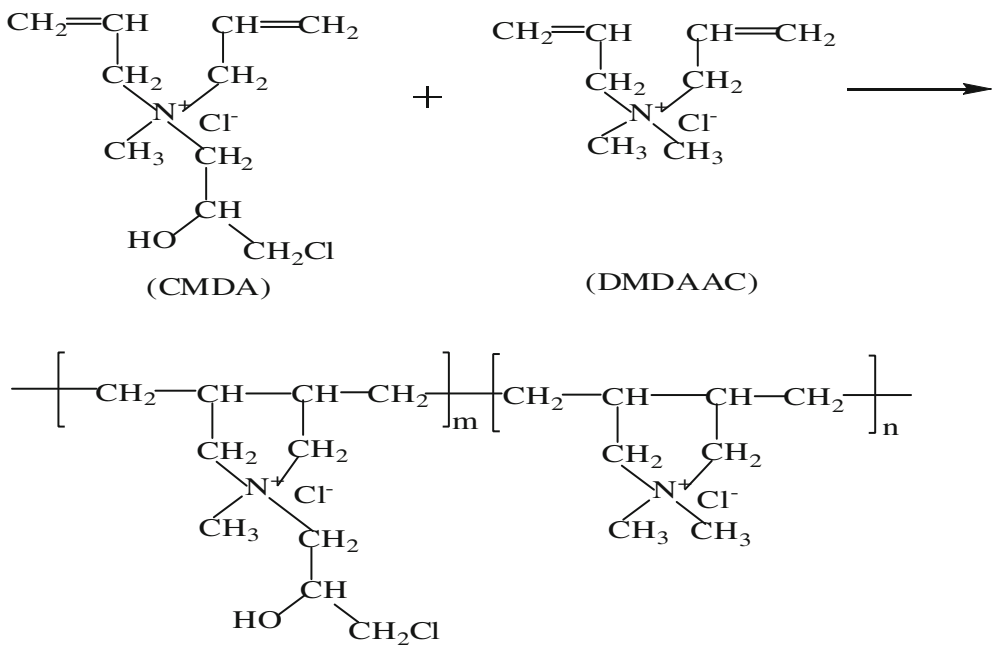

Scheme 1 Design and synthesis of novel P(CMDA-DM)s $m, n=1,2,3,4,5$ 
obtained $\mathrm{P}(\mathrm{CMDA}-\mathrm{DMDAAC})$ s could be controlled by varying molar ratios of raw materials of CMDA to DMDAAC from 2/98 to 20/80 during polymerization, and their molecular weights represented by the intrinsic viscosities of $0.24-0.47 \mathrm{dL} / \mathrm{g}$ or similar were possibly controlled by adjusting different polymerization conditions according to the kinetic chain length equation [24, 25]. Thus, in this article, the effect of different polymerization conditions (polymerization temperatures, polymerization time, monomer concentrations, and initiator amount) on properties of the product, such as intrinsic viscosities and monomer conversions, was first studied in detail to access the method for their molecular weight control. Then, the new method for controlled synthesis of $\mathrm{P}(\mathrm{CMDA}-\mathrm{DMDAAC}) \mathrm{s}$ was designed to synthesize a series of P(CMDA-DMDAAC)s with controlled structures and controlled intrinsic viscosities.

\section{Controlled synthesis processes of $P(C M D A-D M D A A C) s$}

As described in the previous section, the synthesis process of one $\mathrm{P}(\mathrm{CMDA}-$ DMDAAC) product with $10 \%$ molar contents of reactive units (CMDA units) in main chains is here given as an example as follows:

To a 100-ml, round-bottomed flask equipped with a mechanical stirrer, a thermometer, nitrogen inlet and out tubes, calculated amounts of DMDAAC, CMDA, and deionized water were added, to form a $30 \%(\mathrm{w} / \mathrm{w})$ monomer solution. The polymerization solution was warmed to $60{ }^{\circ} \mathrm{C}$, and $6 \%$ amount (w/w, which was equivalent to total monomers amount) of initiator (APS), was added with stirring during a period of $2-3 \mathrm{~h}$ to initiate the polymerization, and then the solution was continuously polymerized at $60{ }^{\circ} \mathrm{C}$ for $3-4 \mathrm{~h}$ (the total polymerization time at $60{ }^{\circ} \mathrm{C}$ was controlled to $6 \mathrm{~h}$ ). Finally, the polymerization solution was further heated to $70{ }^{\circ} \mathrm{C}$ for $2 \mathrm{~h}$. One $\mathrm{P}(\mathrm{CMDA}-\mathrm{DM})$ with $10 \%$ molar contents of reactive units (CMDA units) in main chains and the intrinsic viscosity of $0.37 \mathrm{dL} / \mathrm{g}$ could be synthesized.

Via the same above-mentioned synthesis process, other P(CMDA-DMDAAC)s with reactive units (CMDA units) in main chains and controlled intrinsic viscosities of $0.15-0.76 \mathrm{dL} / \mathrm{g}$ could be synthesized by varying molar ratios of raw materials of CMDA to DMDAAC from $2 / 98$ to $20 / 80$ and increasing initial monomer concentrations from 23 to $40 \%$ with the decrease of initiator amount from 7 to $6 \%$ during polymerization.

\section{Measurements}

The intrinsic viscosities of obtained $\mathrm{P}(\mathrm{CMDA}-\mathrm{DMDAAC}) \mathrm{s}$ accounting for the polymer molecular weights and the monomer conversions were measured according to the literature [6]. The FT-IR spectra of the products in $\mathrm{KBr}$ pellets were recorded using a Nicolet FT-IR (510 P) spectrophotometer. ${ }^{1} \mathrm{H}$ NMR spectra of the polymers were recorded in $\mathrm{D}_{2} \mathrm{O}$ solution on a Bruker DRX-500 (500 MHz) instrument. 


\section{Results and discussion}

Method for controlled synthesis for novel P(CMDA-DMDAAC)s

As described in "Design for controlled-synthesis of P(CMDA-DMDAAC)s", in order to access the controlled synthesis method, this study on the effect of different polymerization conditions on product properties (intrinsic viscosities and monomer conversions) of one P(CMDA-DMDAAC) $10 \%$ molar contents of reactive units (CMDA units) in main chains is here given as an example as follows:

\section{Effect of polymerization temperatures}

The other polymerization conditions were operated the same as shown in "Controlled synthesis processes of $\mathrm{P}(\mathrm{CMDA}-\mathrm{DMDAAC}) \mathrm{s}$ ", and the effect of different initial polymerization temperatures $\left(55-75{ }^{\circ} \mathrm{C}\right)$ on properties of the P(CMDA-DMDAAC) was studied, and the results aere shown in Fig. 1.

The results showed that the intrinsic viscosities of the obtained P(CMDADMDAAC)s were decreased and the monomer conversions were increased with the increase of the initial polymerization temperatures from 55 to $75{ }^{\circ} \mathrm{C}$, because higher polymerization temperatures improved the initiator efficiency, which would produce more radical active centers during polymerization, resulting in more chain terminations which were mainly raised from more mutual collisions between radical active centers, thereby the molecular weights of the obtained P(CMDADMDAAC)s would in turn be lower [26]. On the other hand, higher initiator efficiency would make more monomers become involved in the polymerization in turn, resulting in higher monomer conversions. However, it was also discovered

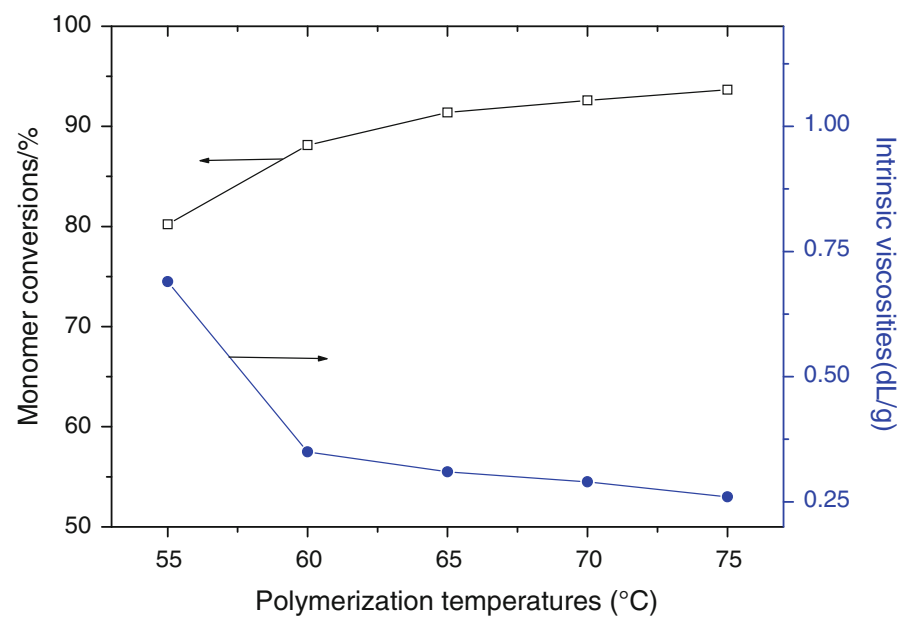

Fig. 1 Effect of polymerization temperatures on properties of the P(CMDA-DMDAAC) $n_{(\mathrm{CMDA})} /$ $n_{(\mathrm{DM})}=10 / 90$, initial monomer concentration $(\mathrm{w} / \mathrm{w}): 30 \%$, initiator amount $(\mathrm{w} / \mathrm{w}): 6 \%$, polymerization time: $6 \mathrm{~h}$ 
that, if the initial polymerization temperature was above $60{ }^{\circ} \mathrm{C}$, the polymerization became very fast and strongly exothermic, resulting in the rapid rise of the polymerization temperature; polymerization was very difficult to control and deviated from the normal state [27]. Thus, the suitable initial polymerization temperature should be $60{ }^{\circ} \mathrm{C}$, in addition, it was not suitable to control the molecular weights of $\mathrm{P}(\mathrm{CMDA}-\mathrm{DMDAAC})$ s by adjusting different initial polymerization temperatures during polymerization, because the scope of useful polymerization temperatures for controlling intrinsic viscosities was very limited. Moreover, when most of the polymerization was accomplished at $60{ }^{\circ} \mathrm{C}$ over a certain time $(6 \mathrm{~h})$, and then the polymerization temperature was further heated to $70{ }^{\circ} \mathrm{C}$ for $2 \mathrm{~h}$, the monomer conversions could be stably further increased (to 95.45 $\%$ ), which could improve the useful ingredients of the obtained P(CMDADMDAAC)s and in turn be beneficial for the development of their dye-fixing properties [27].

\section{Effect of initial polymerization time}

The other polymerization conditions were operated the same as shown in "Controlled synthesis processes of P(CMDA-DMDAAC)s", and the effect of different initial polymerization times $(3-8 \mathrm{~h})$ on the properties of the P(CMDA-DMDAAC) was studied, with the results shown in Fig. 2.

The results showed that the intrinsic viscosities of the obtained P(CMDADMDAAC)s and the monomer conversions were both gradually increased with the extension of initial polymerization time from 3 to $6 \mathrm{~h}$, which indicated that more monomers were involved in the polymerization with the extension of polymerization time, resulting in higher intrinsic viscosities of obtained polymers.

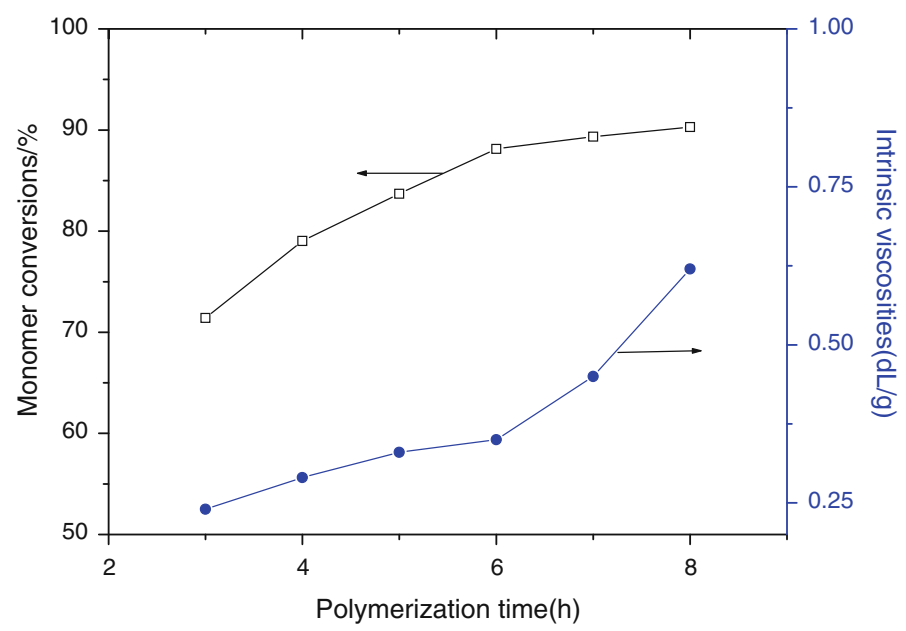

Fig. 2 Effect of polymerization time on properties of the P(CMDA-DMDAAC) $n_{(\mathrm{CMDA})} / n_{(\mathrm{DM})}=10 / 90$, initial monomer concentration (w/w): $30 \%$, initiator amount $(\mathrm{w} / \mathrm{w}): 6 \%: 6 \mathrm{~h}$, initial polymerization temperature: $60{ }^{\circ} \mathrm{C}$ 
However, when the initial polymerization time was further extended to $8 \mathrm{~h}$, the monomer conversions changed little, but the intrinsic viscosities of the obtained $\mathrm{P}(\mathrm{CMDA}-\mathrm{DMDAAC}) \mathrm{s}$ further increased, which could be caused by the unexpected crosslinking reactions. Thus, the suitable initial polymerization time should be $6 \mathrm{~h}$, and therefore it was not suitable to control the molecular weights of P(DHACDMDAAC)s by adjusting different initial polymerization times during polymerization, because the scope of the effect of initial polymerization time on the intrinsic viscosities was very limited.

\section{Effect of initiator amount}

The other synthesis conditions were operated as described in "Controlled synthesis processes of $\mathrm{P}(\mathrm{CMDA}-\mathrm{DMDAAC}) \mathrm{s}$ ", and the effect of different initiator amounts (w/w, 4-8 \%) on the properties of the P(CMDA-DMDAAC) was studied, and the results are shown in Fig. 3.

The results showed that the monomer conversions were gradually increased and the intrinsic viscosities of the obtained P(CMDA-DMDAAC)s were significantly decreased with the increase of initiator amount (w/w) from 3 to $8 \%$, which was in agreement with the kinetic chain length equation [22, 23]. Because larger initiator amounts would produce more radical active centers during polymerization, which would result in more chain terminations which were mainly raised from more mutual collisions between radical active centers or others, thereby their intrinsic viscosities of the obtained $\mathrm{P}(\mathrm{CMDA}-\mathrm{DMDAAC})$ s would be lower in turn. Thus, it could be deduced that the molecular weights of P(CMDA-DMDAAC)s could be controlled by adjusting the initiator amount during polymerization due to the sensitivity of the initiator amount to their intrinsic viscosities.

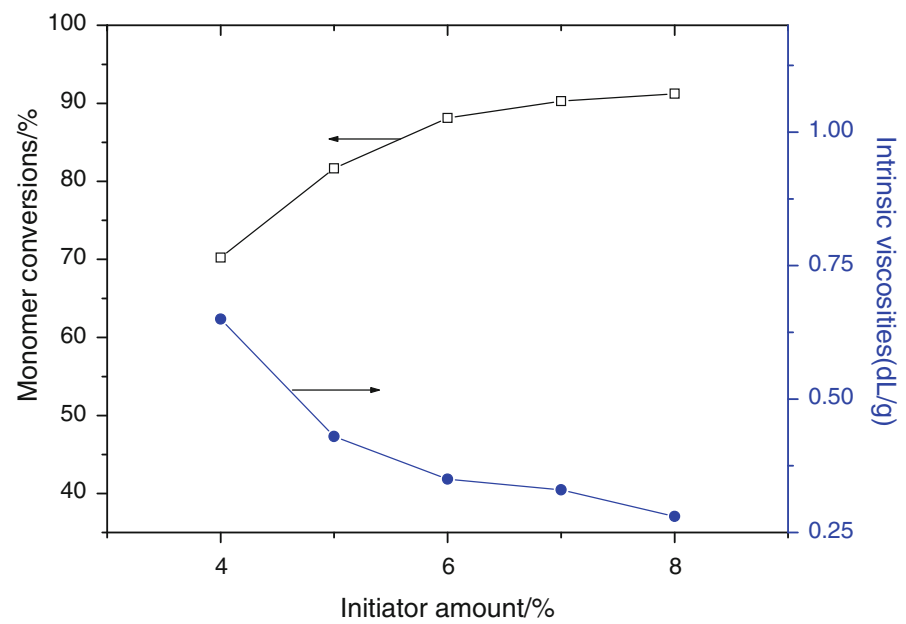

Fig. 3 Effect of initiator amount on properties of the P(CMDA-DMDAAC) $n_{(\mathrm{CMDA})} / n_{(\mathrm{DM})}=10 / 90$, initial monomer concentration $(\mathrm{w} / \mathrm{w}): 30 \%$, polymerization time: $6 \mathrm{~h}$, initial polymerization temperature: $60{ }^{\circ} \mathrm{C}$ 


\section{Effect of initial monomer concentrations}

The other polymerization conditions were operated as described in "Controlled synthesis processes of P(CMDA-DMDAAC)s", and the effect of different initial monomer concentrations (w/w, 28-32 \%) on properties of the P(CMDA-DMDAAC) was studied, the results were shown in Fig. 4.

The results showed that the intrinsic viscosities of P(CMDA-DMDAAC)s and the monomer conversions were both significantly increased with the increase of the initial monomer concentrations during polymerization, which was also in agreement with the kinetic chain length equation [23, 24], because the mutual collisions of the radicals and monomers during polymerization were increased with the increase of initial monomer concentrations, resulting in the increase of the monomer conversions and intrinsic viscosities of the obtained P(CMDA-DMDAAC)s. Therefore, it could be deduced that the molecular weights of P(CMDA-DMDAAC)s could also be controlled by adjusting the initial monomer concentrations during polymerization due to the sensitivity of the initial monomer concentrations to their intrinsic viscosities.

\section{Controlled synthesis of P(CMDA-DMDAAC)s}

According to the basic controlled synthesis processes of $\mathrm{P}(\mathrm{CMDA}-\mathrm{DMDAAC}) \mathrm{s}$ in "Controlled synthesis processes of P(CMDA-DMDAAC)s" and the research results on the effect of different polymerization conditions on the properties of the $\mathrm{P}(\mathrm{CMDA}-\mathrm{DMDAAC}) \mathrm{s}$ in sections "Effect of polymerization temperatures", "Effect of initial polymerization time", "Effect of initiator amount", and "Effect of initial monomer concentrations", a series of novel P(CMDA-DMDAAC)s with 2-20\% molar contents of reactive units (CMDA units) in main chains and

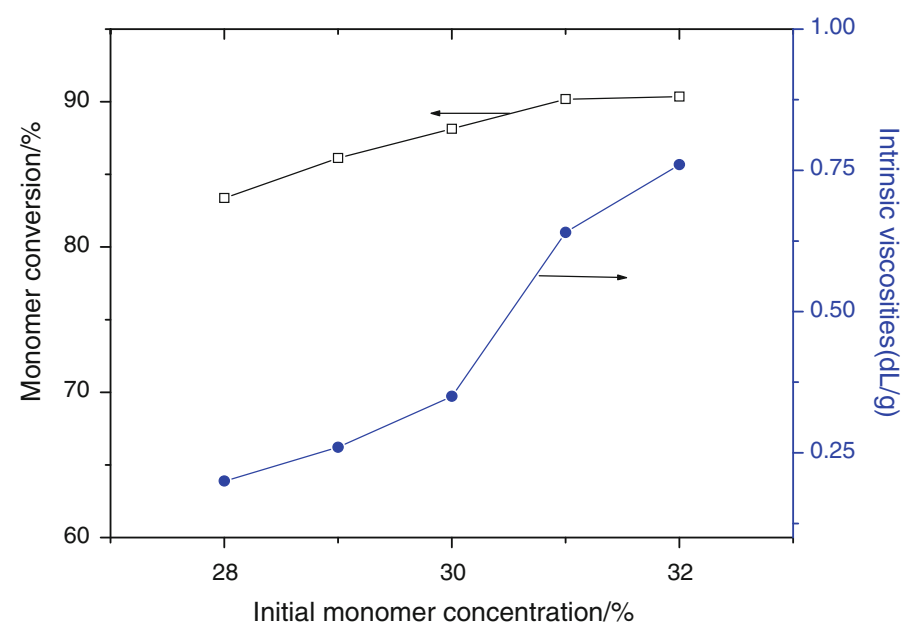

Fig. 4 Effect of initiator monomer concentrations on properties of the P(CMDA-DMDAAC) $n_{(\mathrm{CMDA})} /$ $n_{(\mathrm{DM})}=10 / 90$, polymerization time: $6 \mathrm{~h}$, initiator amount $(\mathrm{w} / \mathrm{w}): 6 \%$, initial polymerization temperature: $60{ }^{\circ} \mathrm{C}$ 
controlled intrinsic viscosities of $0.15-0.76 \mathrm{dL} / \mathrm{g}$, which were designed as useful polycationic dye-fixatives on cotton fabric, were synthesized by varying molar ratios of raw materials of CMDA to DMDAAC from 2/98 to 20/80 and increasing initial monomer concentrations from 23 to $40 \%$ with the decrease of initiator amount from 7 to $6 \%$ during polymerization, under the same conditions that the polymerization was kept at $60{ }^{\circ} \mathrm{C}$ for $6 \mathrm{~h}$ and then ripened at $70{ }^{\circ} \mathrm{C}$ for $2 \mathrm{~h}$. The results are given in Table 1.

\section{FT-IR and ${ }^{1} \mathrm{H}$ NMR analysis of P(CMDA-DMDAAC)s}

The structures of obtained P(CMDA-DMDAAC)s could be confirmed by FT-IR and ${ }^{1} \mathrm{H}$ NMR analysis according to the operation process in "Measurements".

Table 1 Controlled synthesis of P(CMDA-DMDAAC)s

\begin{tabular}{|c|c|c|c|c|c|}
\hline $\begin{array}{l}\text { P(CMDA - } \\
\text { DMDAAC) }\end{array}$ & $\begin{array}{l}\left.n_{(\mathrm{CMDA})}\right) / n \\
(\mathrm{DMDAAC})\end{array}$ & $\begin{array}{l}\text { Initial monomer } \\
\text { concentration } \\
(\mathrm{w} / \mathrm{w}) / \%\end{array}$ & $\begin{array}{l}\text { Initiator amount } \\
(\mathrm{w} / \mathrm{w}) / \%\end{array}$ & $\begin{array}{l}\text { Intrinsic } \\
\text { viscosities } \\
\text { (dL/g) }\end{array}$ & $\begin{array}{l}\text { Monomer } \\
\text { conversion/\% }\end{array}$ \\
\hline 1 & $2 / 98$ & 35 & 7 & 0.19 & 96.64 \\
\hline 2 & $2 / 98$ & 36 & 7 & 0.22 & 96.75 \\
\hline 3 & $2 / 98$ & 37 & 6 & 0.26 & 96.45 \\
\hline 4 & $2 / 98$ & 38 & 6 & 0.37 & 96.69 \\
\hline 5 & $2 / 98$ & 39 & 6 & 0.40 & 96.90 \\
\hline 6 & $2 / 98$ & 40 & 6 & 0.49 & 96.96 \\
\hline 7 & $4 / 96$ & 32 & 7 & 0.20 & 95.13 \\
\hline 8 & $4 / 96$ & 33 & 7 & 0.24 & 95.88 \\
\hline 9 & $4 / 96$ & 34 & 6 & 0.28 & 95.85 \\
\hline 10 & $4 / 96$ & 35 & 6 & 0.39 & 96.07 \\
\hline 11 & $4 / 96$ & 36 & 6 & 0.46 & 96.17 \\
\hline 12 & $4 / 96$ & 37 & 6 & 0.57 & 96.91 \\
\hline 13 & $6 / 94$ & 30 & 7 & 0.20 & 94.80 \\
\hline 14 & $6 / 94$ & 31 & 7 & 0.25 & 95.11 \\
\hline 15 & $6 / 94$ & 32 & 6 & 0.28 & 95.32 \\
\hline 16 & $6 / 94$ & 33 & 6 & 0.41 & 95.88 \\
\hline 17 & $6 / 94$ & 34 & 6 & 0.55 & 96.18 \\
\hline 18 & $8 / 92$ & 28 & 7 & 0.17 & 94.65 \\
\hline 19 & $8 / 92$ & 30 & 6 & 0.26 & 93.93 \\
\hline 20 & $8 / 92$ & 31 & 6 & 0.32 & 95.16 \\
\hline 21 & $8 / 92$ & 32 & 6 & 0.50 & 95.66 \\
\hline 22 & $10 / 90$ & 28 & 7 & 0.16 & 94.86 \\
\hline 23 & $10 / 90$ & 30 & 6 & 0.37 & 95.45 \\
\hline 24 & $10 / 90$ & 31 & 6 & 0.69 & 95.37 \\
\hline 25 & $20 / 80$ & 23 & 7 & 0.15 & 93.49 \\
\hline 26 & $20 / 80$ & 24 & 6 & 0.23 & 93.00 \\
\hline 27 & $20 / 80$ & 25 & 6 & 0.76 & 95.64 \\
\hline
\end{tabular}




\section{FT-IR analysis of $P(C M D A-D M D A A C) s$}

The FT-IR analysis of obtained P(CMDA-DMDAAC)s is shown in Fig. 5.

Figure 5 shows that the FT-IR spectra (peak 1) of all the P(CMDA-DMDAAC)s were similar to that of PDMDAAC, and all the spectra had the absorptions of the $\mathrm{CH}_{3}$ groups at $3,013 \mathrm{~cm}^{-1}$, the absorptions of the $-\mathrm{CH}_{2}-$ linkage at $2,941 \mathrm{~cm}^{-1}$, and the absorptions of the methyne linkage at $2,865 \mathrm{~cm}^{-1}$, which could be attributed to the DMDAAC units, indicating that the structures of the obtained P(CMDADMDAAC)s were based on PDMDAAC.

Compared to the FT-IR spectra of PDMDAAC (curve $\mathrm{c}$ in Fig. 5), the FT-IR spectra of the obtained P(CMDA-DMDAAC)s (curves $d-g$ in Fig. 5) exhibited the new different characteristic absorptions at $1,109 \mathrm{~cm}^{-1}$ (peak 2) which was shifted from that of the CMDA monomer at $1,105 \mathrm{~cm}^{-1}$ (peak 5), as well as the other similar absorptions of the DMDAAC units, and those absorptions were increased with the increase of contents of the CMDA units in the structures of the P(CMDADMDAAC)s, which could be attributed to the CMDA units in the main chains of the P(CMDA-DMDAAC)s.

Moreover, the bending absorptions of the $=\mathrm{CH}$ linkage at $884 \mathrm{~cm}^{-1}$ (peak 3, which was attributed to the DMDAAC monomer) and $849 \mathrm{~cm}^{-1}$ (which was attributed to the CMDA monomer), and the absorption of CMDA monomer at $2,332 \mathrm{~cm}^{-1}$ (peak 4), were all absent in the P(CMDA-DMDAAC)s' FT-IR absorptions, indicating that the expected copolymerization of the CMDA monomer with the DMDAAC monomer occurred.

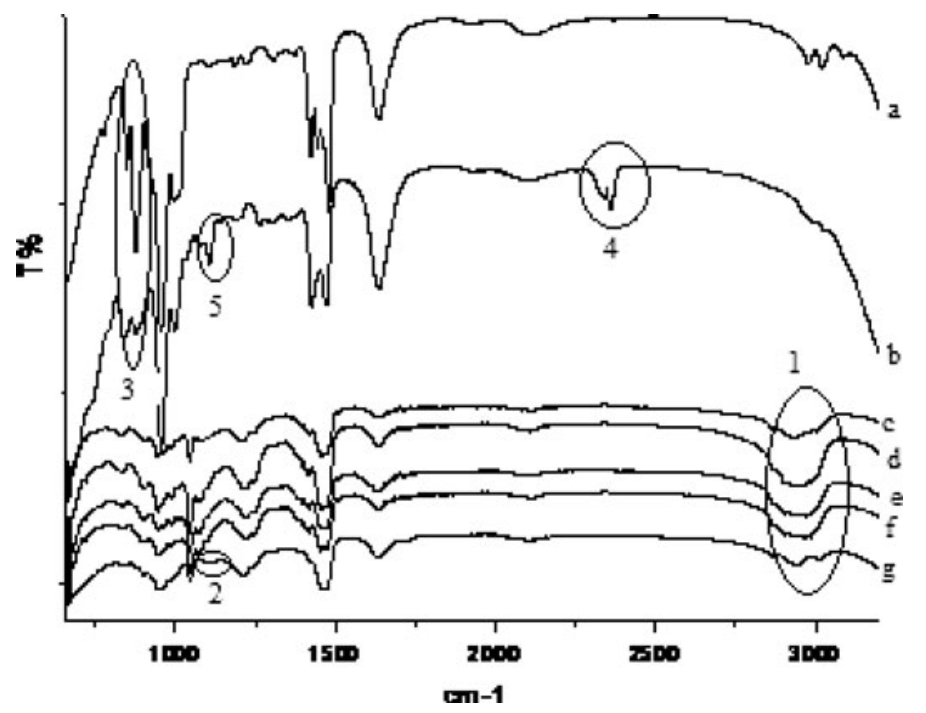

Fig. 5 FT-IR analysis of P(CMDA-DMDAAC)s. a DMDAAC (monomer), b CMDA (monomer), c PDMDAAC (0\% molar contents of CMDA), d $2 \%$ molar contents of CMDA (No. 2), e $6 \%$ molar contents of CMDA (No. 14), f $10 \%$ molar contents of CMDA (No. 22), g $20 \%$ molar contents of CMDA (No. 26) 
Thus, it could be indicated from the above-mentioned FT-IR results that the structures of the obtained P(CMDA-DMDAAC)s were as expected.

\section{${ }^{1} H$ NMR analysis of $P(C M D A-D M D A A C) s$}

The ${ }^{1} \mathrm{H}$ NMR analysis of the obtained PDMDAAC, one P(CMDA-DMDAAC), and CMDA monomer are, respectively, shown in Figs. 6, 7, and 8.

It is shown in Fig. 6 that the ${ }^{1} \mathrm{H}$ NMR spectra of the PDMDAAC had the characteristic peak of a $\mathrm{N}^{+}-\mathrm{CH}_{2}$ - linkage in the DMDAAC unit at $3.75 \mathrm{ppm}$ (peak 1), a $-\mathrm{CH}_{3}$ group at 3.06-3.15 ppm (peak 2), a methyne unit at $2.63 \mathrm{ppm}$ (peak 3), and the $-\mathrm{CH}_{2}-$ linkage at $1.25-1.43$ ppm (peak 4).

Figure 7 shows that the ${ }^{1} \mathrm{H}$ NMR spectra of No. 26 of the P(CMDA-DMDAAC) samples (CMDA-modified PDMDAAC) had the characteristic peak of a N ${ }^{+}-\mathrm{CH}_{2}-$

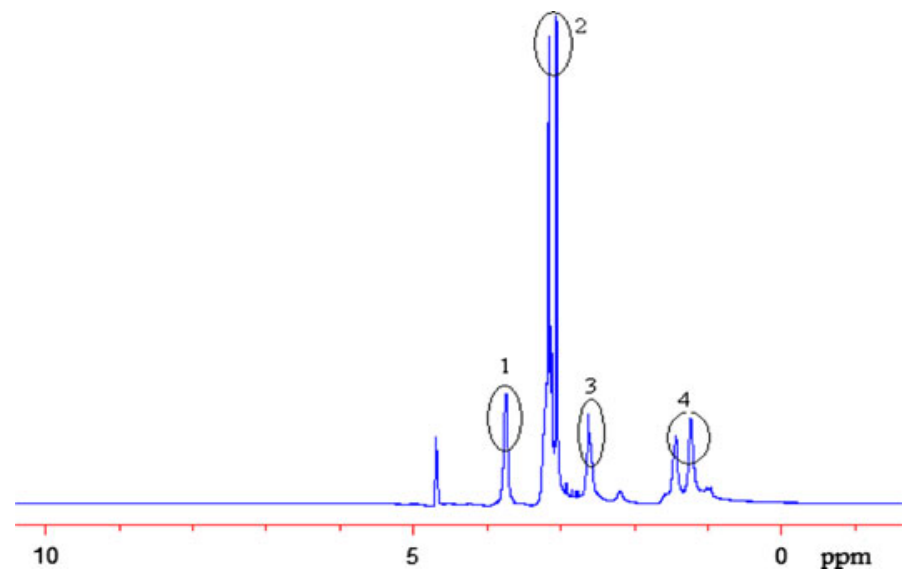

Fig. $6{ }^{1} \mathrm{H}$ NMR analysis of PDMDAAC

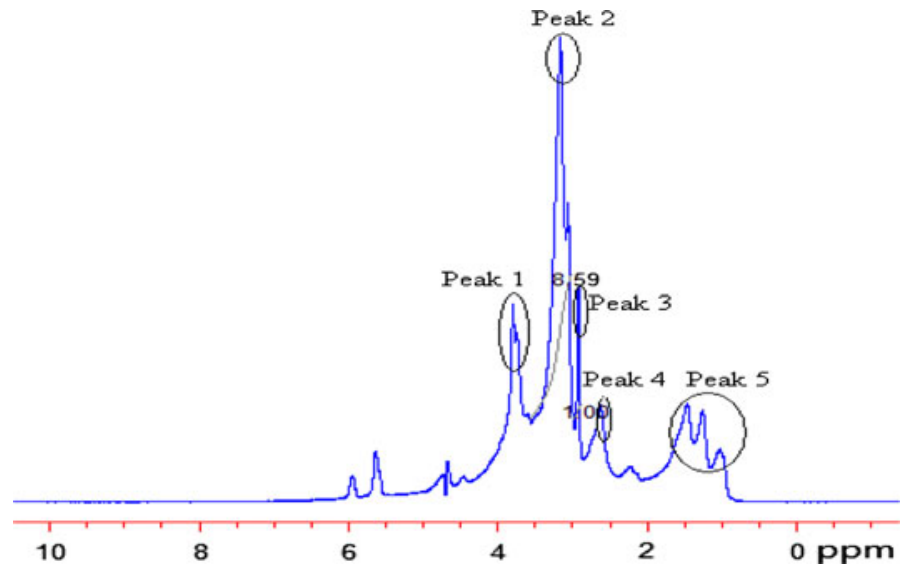

Fig. $7{ }^{1} \mathrm{H}$ NMR analysis of one P(CMDA-DMDAAC) (No. 26) 


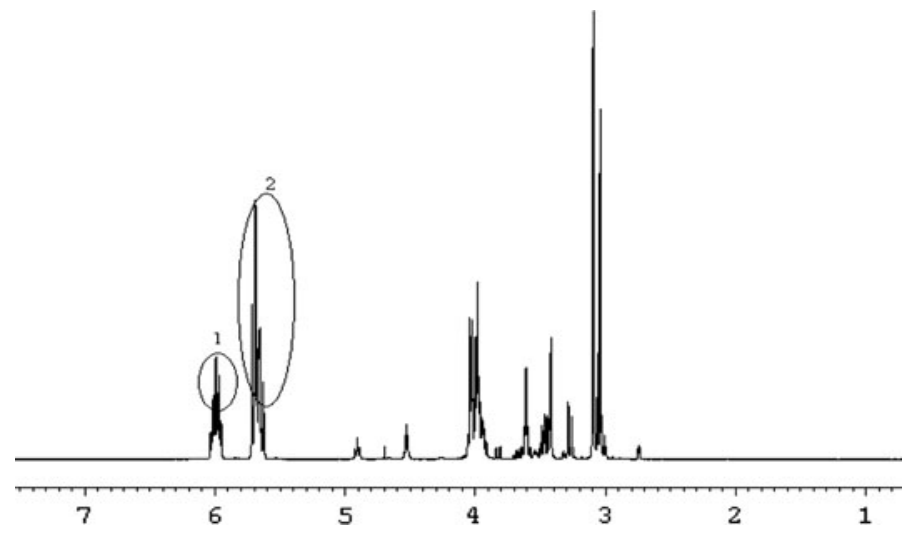

Fig. $8{ }^{1} \mathrm{H}$ NMR analysis of CHMDAAC

linkage in the DMDAAC unit at 3.74-3.79 ppm (peak 1), a $-\mathrm{CH}_{3}$ group at 3.06-3.16 ppm (peak 2), a methyne unit at $2.63 \mathrm{ppm}$ (peak 4), and the $-\mathrm{CH}_{2}-$ linkage at 1.02-1.46 ppm(peak 5), which were similar to those of the PDMDAAC and could be attributed to the DMDAAC units in main chains.

In addition, compared to the ${ }^{1} \mathrm{HNMR}$ spectra of PDMDAAC (Fig. 6), the spectra of the $\mathrm{P}(\mathrm{CMDA}-\mathrm{DMDAAC})$ had the clear new characteristic peak of a- $\mathrm{CH}_{3}$ group at $2.91 \mathrm{ppm}$ (peak 3 in Fig. 7), which could be attributed to the CMDA units in main chains.

Compared to the ${ }^{1} \mathrm{H}$ NMR spectra of the monomer (CMDA) (Fig. 8) and that of DMDAAC monomer in the literature [28], the characteristic peak of a $\mathrm{CH}_{2}=\mathrm{CH}-$ linkage at 5.62-6.00 ppm (which was attributed to the CMDA; peaks 1 and 2 in Fig. 8) and 5.50-6.43 ppm (which was attributed to the DMDAAC monomer, literature values) were both absent, further indicating that the expected copolymerization of the CMDA monomer with the DMDAAC monomer occurred.

Moreover, the molar ratio of characteristic peak area between the $-\mathrm{CH}_{3}$ groups in the CMDA units and the values in the DMDAAC units could be calculated at 1:8.59 (Fig. 6), which was in agreement with the theoretical value (1:8), confirming the possible structures of the P(CMDA-DMDAAC)s.

Thus, the ${ }^{1} \mathrm{H}$ NMR spectra further indicated that the structures of the obtained P(CMDA-DMDAAC)s were as expected.

\section{Conclusions}

A series of novel $\mathrm{P}(\mathrm{CMDA}-\mathrm{DM}) \mathrm{s}$ with controlled structures and controlled intrinsic viscosities of $0.15-0.76 \mathrm{dL} / \mathrm{g}$, were successfully synthesized by varying molar ratios of raw materials of CMDA to DM from 2/98 to 20/80, and increasing initial monomer concentrations from 23 to $40 \%$ with the decrease of initiator amount from 7 to $6 \%$ during polymerization. FT-IR analysis and ${ }^{1} \mathrm{H}$ NMR analysis confirmed their structures, which were as designed and could be expected to be novel useful reactive polycationic dye-fixatives on cotton fabric. 
Open Access This article is distributed under the terms of the Creative Commons Attribution License which permits any use, distribution, and reproduction in any medium, provided the original author(s) and the source are credited.

\section{References}

1. H.F. Wang, Y.Y. Cheng, H. Lin, J. Soochow Univ. (Engineering Science Edition) 23(4), 12 (2003)

2. J. Zhang, Fine Specialty Chem. 12(8), 1 (2004)

3. J.X. Ye, Modern Fabric Technol. 11(2), 43 (2003)

4. C. Wandrey, B.J. Hernandez, D. Hunkerler, Adv. Polym. Sci. 145, 123 (1999)

5. X. Jia, Y.J. Zhang, Fine Chem. 25(10), 1008 (2008)

6. Y.M. Deng, J. Dongguan Univ. Technol. 17(1), 51 (2010)

7. R.S. Blackburn, S.M. Burkinshaw, J. Appl. Polym. Sci. 89, 1026 (2003)

8. S.M. Burkinshaw, A. Gotsopoulos, Dyes Pigm. 42, 179 (1999)

9. S.M. Burkinshaw, A. Gotsopoulos, Dyes Pigm. 32(4), 209 (1996)

10. S.M. Burkinshaw, D. Katsarelias, Dyes Pigm. 29(2), 139 (1995)

11. X. Zhang, B. Mao, M.H. Xiang, Textile Auxiliaries 22(2), 5 (2005)

12. W. Li, H. Hong, H. Zhang, J. Beijing Inst. Clothing Technol. 28(2), 19 (2008)

13. W. C. QU, Dissertation, Nanjing: Nanjing University of Science and Technology, 1998

14. Y.K. Yu, Y.J. Zhang, J. Vinyl. Add. Tech. 16(4), 277 (2010)

15. K. Komiya, S. Kanai, K. Beppu, Japan Patent 63,264,985, 1 Nov 1988

16. H.T. Yang, X.D. Zhou, J. Dong, Dye Printing 5, 10 (2010)

17. X.H. Chen, J.X. Yang, J Nantong Univ (Natural Science Edition) 8(2), 47 (2009)

18. J.X. Yang, X.H. Chen, Textile Auxiliaries 26(3), 23 (2009)

19. Y.H. Mao, Y. Guan, Q.K. Zheng, Dye Printing 14, 1 (2010)

20. Y.K. Yu, Y.J. Zhang, J. Textil. Res. 31(11), 145 (2010)

21. F. A. Daniher, J. R. Aspland, U.S. Patent, 4,735,628, 5 April 1988

22. S. Saima, A. Saeed, Chin. J. Chem. 26, 553 (2008)

23. Y.K. Yu, Y.J. Zhang, Fine Chemicals 28(4), 400 (2011)

24. Z.R. Pan, Polymer Chemistry, 3rd edn. (Beijing Chemical Industry Press, Beijing, 2003), p. 43

25. Q.J. Dong, J.L. Tang, Q.Q. Liang, Leather Sci. Eng.16(1), 26 (2006)

26. X. Jia, Y.J. Zhang, Chin. J. Appl. Chem. 24(6), 610 (2007)

27. X. Jia, Y.J. Zhang, P.Z. Yu, Petrochem. Technol. 37(1), 49 (2008)

28. R.F. Zhu, G.N. Fan, H.Q. Yu, J. Anhui Univ. (Natural Science Edition) 30(1), 71 (2006) 